\title{
Written word and spatial experience
}

\section{Sensemaking, architecture and cognition}

\section{Narrative space}

Açalya Allmer's compelling article (arq 13.2, pp. 163-71) on Orhan Pamuk's Museum of Innocence raises some intriguing issues with regards to the notion of narrative space.

Museum of Innocence refers to both Pamuk's 2008 novel and his Istanbul museum due to open next year, which together constitute a project in which fiction and reality are surreally conflated. Novel and museum are simultaneously separate entities, yet intrinsically interlinked, with Orhan describing them as 'two representations of one single story perhaps'. Parallels between the written word and museological space - or Orhan's writing and curating - are palpably strong. Both are concerned with capturing time. In the novel this is the time between the 1970 s and 20oos; the time of the main protagonist, Kemal's, personal infatuation with Füsun, overlaid with events from the collective history of Turkey. In the museum, the concern is the transformation of this time into a space, in which, as Pamuk intends, "[t]he whole world and the present are left behind. We are in a different atmosphere, a different time'. Both narrative vehicles of text and physical archive also have an objectbased encyclopaedic intent. The novel 'becomes an exhaustive catalogue of Fusun's [...] belongings', while the museum as Wunderkammer is a repository of these self-same things, with the house itself a revealing object in the collection. Lastly the motivation of pride in the act of collection links novel and museum, with the implicit desires for publicity and permanence being shared by both.

Commonalities exist, then, between the writing and curating of the Museum of Innocence, but what is really fascinating is the act and success of translation of the story into the two different media - the written word and the spatial experience. Here Allmer believes Pamuk to be 'aware of the difficulties of translating a verbal narrative that unfolds in the imagination of the reader into an architectural space', and warns that the Museum of Innocence 'should not be considered as an architectural adaptation of the story'. This distanciation from literal spatial translation is clear in the architectural treatment, which

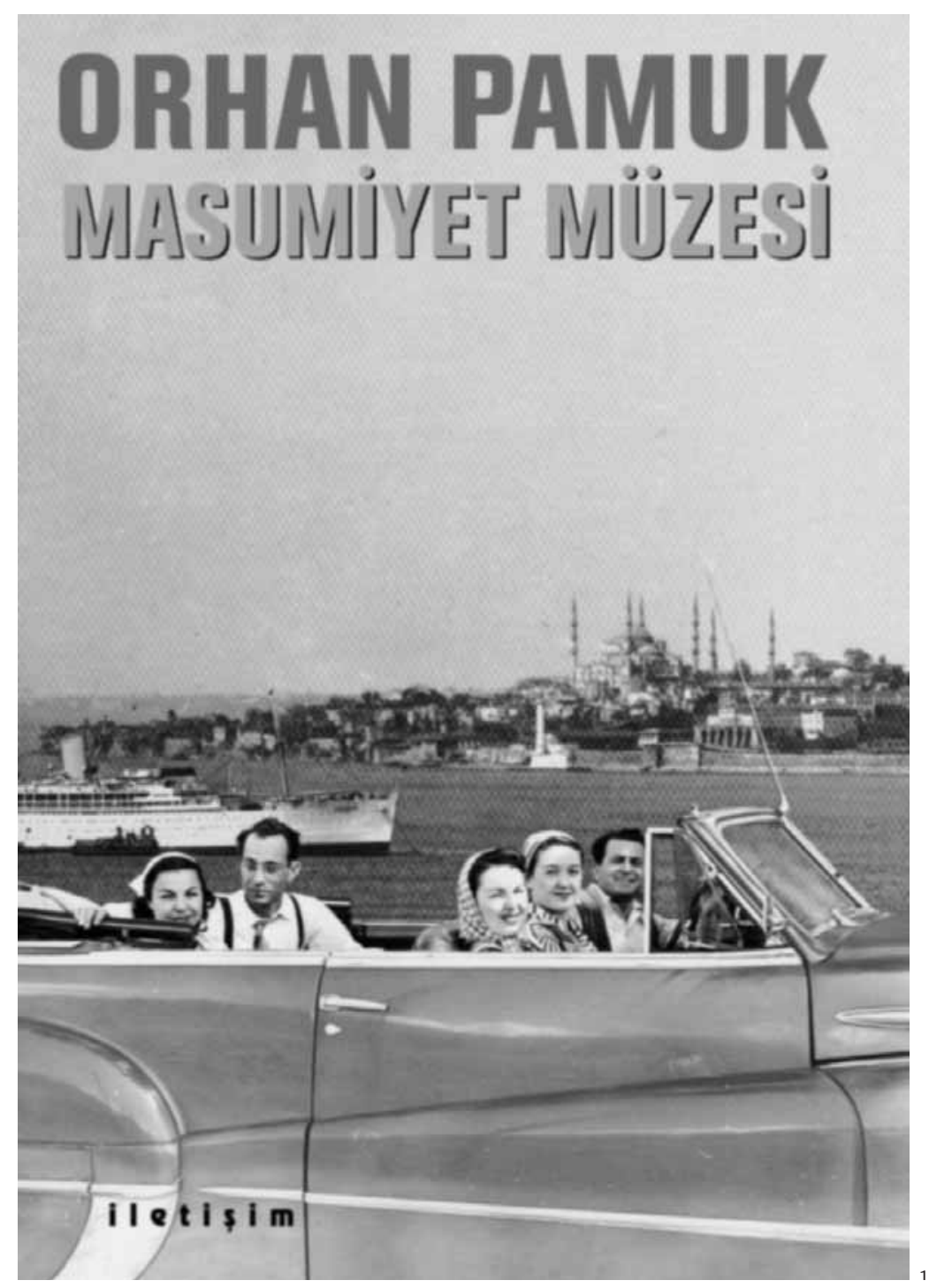


favours the pragmatics of visitor circulation over the use of existing found space as memory repository. Both the container (house) and contained (collection of personal artefacts derived from the novel) enable a material representation of the story, but how can the vivid world of the imagination, as provoked by the novel, be conjured up architecturally? Or how can ekphrasis - the expression of an image in words - be successfully reversed? How can intangible 'atmosphere', seemingly lost in architectural translation, enrich visitor experience and elevate curatorial space to narrative space?

These questions underpin a forthcoming conference - Narrative Space - organised in collaboration between the University of Leicester's School of Museum Studies and the University of Nottingham's Department of the Built Environment, to be held between 20 and 22 April, 2010

(www.le.ac.uk/ms). Narrative Space is an international interdisciplinary conference exploring the creation of narrative environments in museums, galleries, historic sites, buildings and landscapes. From the level of the site and the building down to the level of the exhibition and the object, it will ask how environments can be created which tell stories of people, of places and of collections. It will address this issue, pertinent to the Museum of Innocence, as to how spaces, objects and a range of media can be utilised to create spatial experiences which go beyond a traditional literal or linear mode of storytelling, to become threedimensionally engaging, meaningful and memorable.

The Museum of Innocence in both its facets is deftly revealed by Allmer as a rich and complex project. However, its transportative power may be seen to reside largely in the narrative of the novel, rather than the narrative space of the museum. The unlocking of this potential narrative space within the contemporary museum is an exciting and relevant challenge.

LAURA HANKS Nottingham

Laura Hanks is Associate Professor in the Department of the Built Environment, University of Nottingham

Laura Hanks acknowledges Suzanne MacLeod (School of Museum Studies, University of Leicester) and Jonathan Hale (Department of the Built

Environment, University of Nottingham)

\section{Intrinsic legibility}

Who could deny the rise of social media, considered by Richard Coyne in his paper 'Interpretative communities as decisive agents: on pervasive digital technologies' in (arq 13.2, pp. 127-32)? Some among us might shrink from messaging al day, as if one still needs time to do things worth messaging about; but I, for one, sense how that stance has its costs and benefits, like any lifestyle choice, such as choosing not to drink.

Social media indeed took the White House last year. Plainly the Internet beat television. As one among five million I send a few dollars to MoveOn when I can, and together we add up! Social media advance local causes and values as well. As recent Nobel laureate Elinor Ostrom reminds us, the future of the commons is in the hands of neither the market nor the state. Design advocates such as Paul Hawken and John Thackara estimate millions of participants in thousands of organisations dedicated to creating and maintaining economic value. This isn't just a long tail of things formerly too insignificant to monetise, but a full-scale transformation of what constitutes economic activity. By now any schoolboy knows that Gross Domestic Product has failed as a measurement. Meanwhile, notions of social production have arrived, at such basics as electrification and food security. Weak social ties over networks appear to complement, and not diminish, strong ties in unmediated proximity in the upkeep of local value. Yochai Benkler, a much admired authority on 'nonmarket production', observed in The Wealth of Networks: 'We have new opportunities for building sustained, limited purpose relations, weak and intermediate-strength ties, that have significant roles in providing us with context [...]'.

It is toward this actuality, 'place

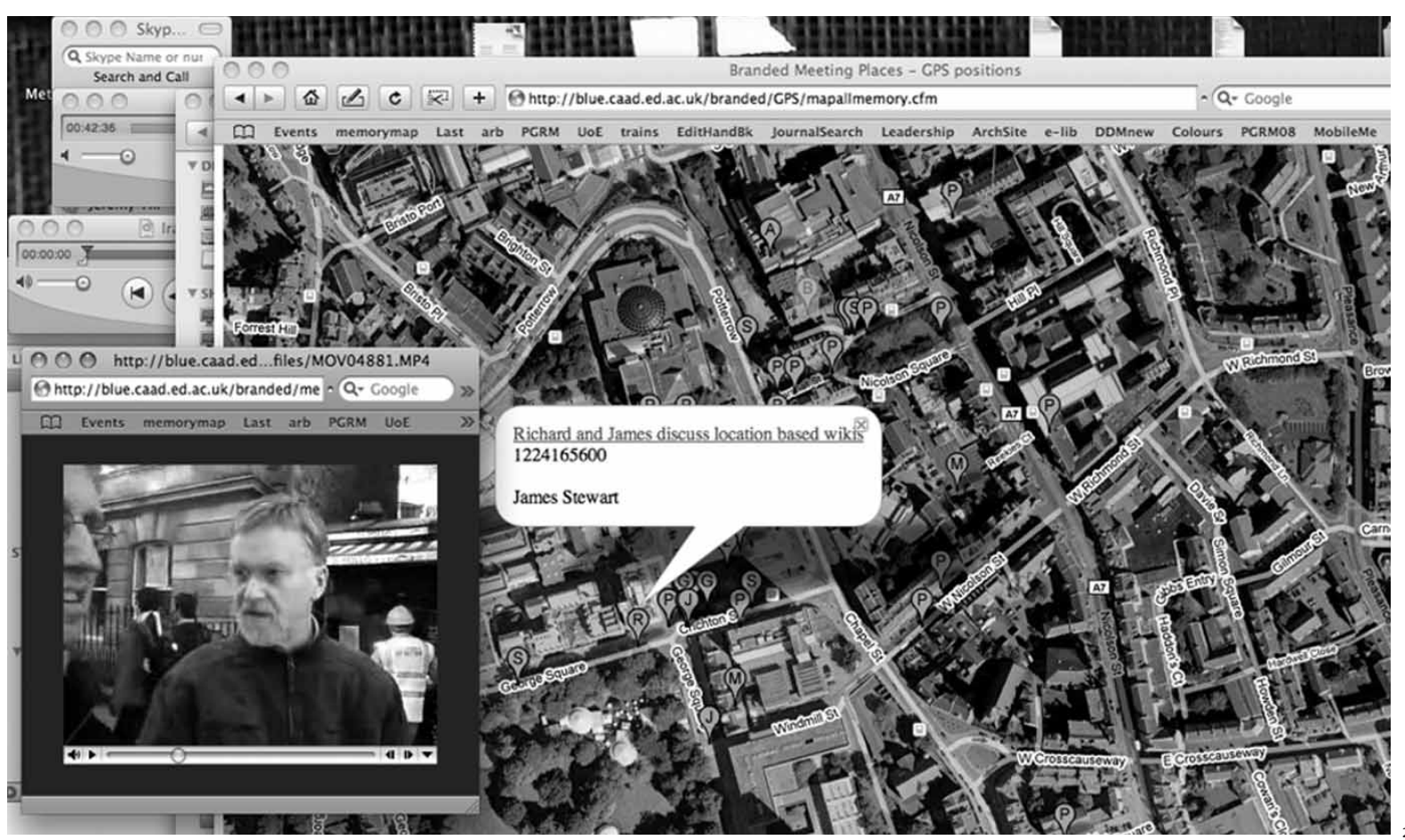

Mobile innovations in Edinburgh: environment becomes library 
as a source and medium of agency', that I see a contribution in Richard Coyne's fine essay on distributed agency. What Coyne calls 'cognitive scaffolding', an appealing turn of phrase, others might call protocols, props or cues. The activity theory that Coyne interprets through Latour, and back to Vygotsky, emphasises the role of such contingent aspects of context toward the shaping and shifting of intent. Intentionality remains a best critique of analytical behaviouralism ('long-discredited theories of environmental determinism'), a movement that long sidetracked the discipline of architecture's engagement with the discipline of cognitive psychology. Now as information overload moves sensemaking to the forefront again, architecture must reconsider cognition. Some earlier notions, such as the developmental learning principle of 'construct adjustment', seem more relevant than ever.

Yet such mainstream debate on Web 2.o seldom dwells on the role of architecture and urbanism in socially networked sensemaking. Is this why Coyne turns to Bakhtin and not Benkler on degree of subjectivity, or to Gadamer and not, say, David Weinberger on how understanding happens? To me, it's a matter of attention economics. Architecture's role is to reduce the need for more explicit cognitive scaffolding. The intrinsic structure of the world is not information in the sense of coded symbolic communication. Yet it orients, and provides referents for communications, lest they be taken for the world itself, as ever some digerati seem ready to accept. For however remarkable the map has become, it is still not the territory.

Let me close with a street level instance. Recently my neighbourhood car wash installed printed signs asking 'to get more water pressure, please squeeze the trigger on the wand'. Who knew? Indeed somebody worked hard to design a wand with one big handle whose one affordance is not only obvious, but fun. So why the signs? Love of signposting, deeply realitychallenged customers, or just information pollution? Industrial design (of that handle) should preempt the information glut in this case. Architecture can do so in larger cases, and larger still, a city might still have intrinsic legibility. At all these scales, embodiment still makes sense.
Malcolm McCullough is Associate Professor at the Taubman College of Architecture and Planning, University of Michigan

\section{Illustration credits}

arq gratefully acknowledges:

Orhan Pamuk, 1

Richard Coyne, 2

Letters for publication should be sent to:

Richard Weston

arq

The Welsh School of Architecture

Cardiff University

Bute Building

King Edward VII Avenue

Cardiff CF10 3 NB, UK

$\mathrm{T}:+44$ (29) 20874431

$\mathrm{F}:+44$ (29) 20874926

E:WestonR1@cardiff.ac.uk

The Editors reserve the right to shorten letters 